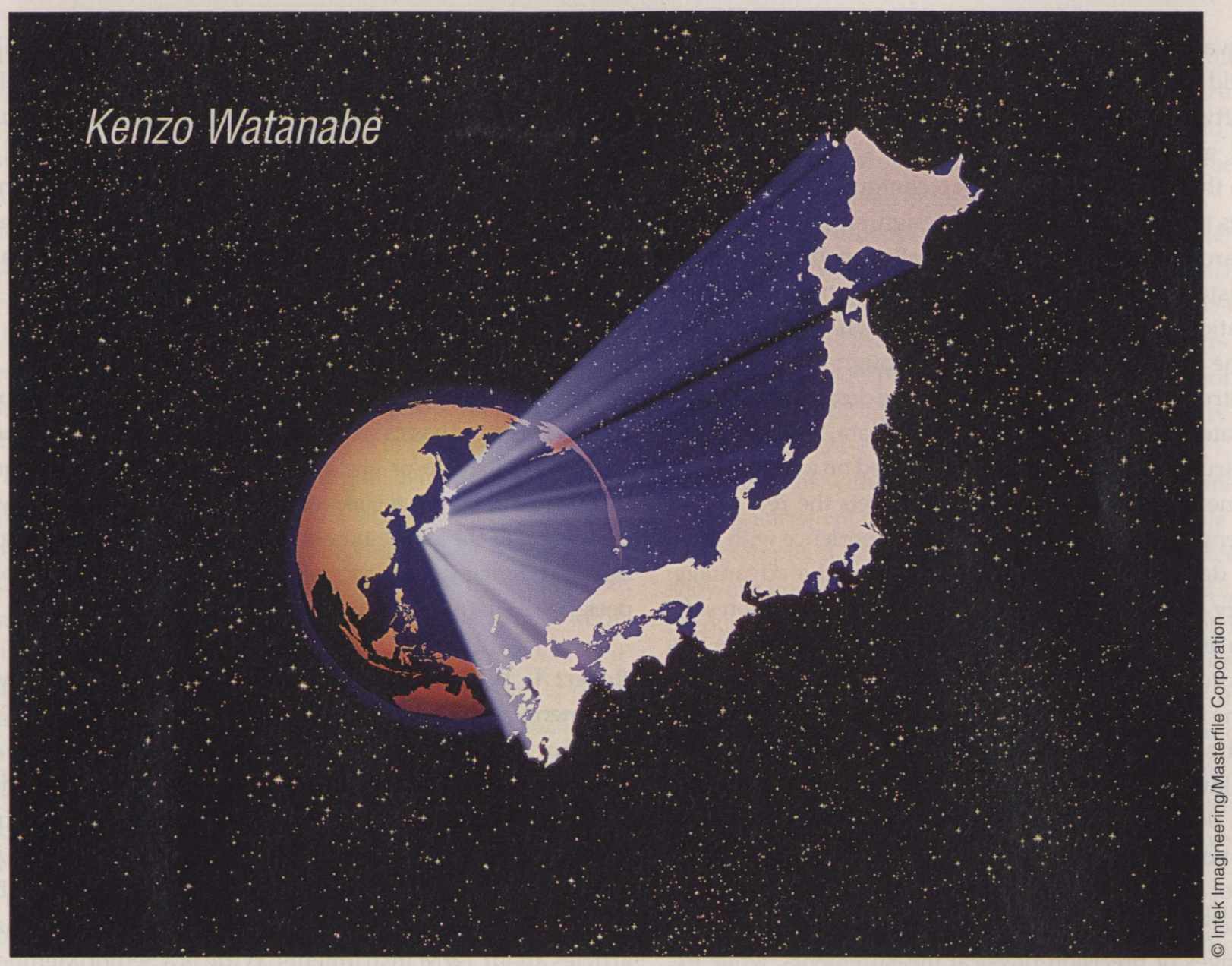

\title{
Instrumentation Education in Japan: Despair and Expectation
}

ndustrial products made in Japan have a good reputation for their high quality. This excellent state of affairs can be directly attributed to the national character of defining, and strictly adhering to, standards of performance and behavior. However, we are now at a crossroads.

For engineers, standards and specifications are the rules that guide both product development and manufacturing. Engineers must devote most of their time and effort to performing tests and data analysis. The level of effort varies, depending on whether it is for quality control on a manufacturing line or for the design and qualification of new products and processes. However, patient dedication to such tedious work has successfully produced high-quality industrial products. The foundation of quality in manufacturing and design is I\&M. That is, I\&M provides the foundation for modern industry.
It is somewhat surprising that I\&M has never been a major curriculum at universities. The closest curriculum is electrical and electronics engineering (EE), which requires 124 credits to graduate. The typical EE program has mandatory courses in mathematics, electromagnetics, circuit theory, electric and electronic circuits, solid-state physics, semiconductor materials and devices, as well as other elective courses. For measurement, only two-credit (1.5 hrs/wk x $20 \mathrm{wks})$ or three-credit ( $1.5 \mathrm{hrs} / \mathrm{wk}$ x $40 \mathrm{wks}$ ) core courses are provided. The topic coverage is necessarily brief, limited to the fundamental topics listed in Tables 1 and 2. In addition to these core courses, a two-credit optional course, "Sensors," covers measurements of non-electrical variables.

Although playing a relatively minor role in lecture-course content, measurement actually occupies a substantial portion 
Table 1. Syllabus of Three-Credit "Electromagnetic Measurements" Course

\author{
Fundamentals of Measurements \\ General Remarks \\ Methodology \\ Measurement Errors \\ Units and Standards \\ International Units \\ Established Units and Standards \\ Electrical Instruments \\ General Indicating Instruments \\ Moving-Coil Instruments \\ Power Meters \\ Recorders \\ Voltage and Current Measurements \\ Potentiometers \\ Current and Magnetic-Field Measurements \\ Voltage and Current References \\ Resistance Measurements \\ Resistance Bridges \\ Low- and High-Resistance Measurements \\ Standard Resistors \\ Impedance Measurements \\ Inductance Measurements \\ Capacitance Measurements \\ AC Bridges \\ Q Meters \\ Inductance and Capacitance Standards \\ Power Measurements \\ DC Power Measurements
}

AC Power Measurements

Power Meters

Frequency and Time Measurements

Frequency Standards

Frequency Measurements

Time Measurements

Waveform, Phase, and Spectrum Measurements

Oscilloscopes

Phase Meters

Spectrum Analyzers

Distortion Measurements

Magnetic Measurements

Magnetic-Field Measurements

B-H Hysteresis of Magnetic Materials

Iron-Loss Measurements

Instrumentation Amplifiers

Negative-Feedback Amplifiers

Op-Amps

Electronic Ammeters and Voltmeters

Analog Electronic Instruments

Digital Voltmeters

Signal Sources

Voltage and Current References

Oscillators

Signal Detection

DC Amplifiers

Bandpass Amplifiers

Synchronous Detectors of lab experiments, which are part of a mandatory four-credit course. Typical experiments include:

- Component measurements

- Characterization of bipolar transistors, FETs, and op-amps

- Breadboarding amplifiers and oscillators and their performance measurements

- Microwave impedance measurements

- Performance measurements of optical devices

- Fabrication of diodes and transistors and their characterization

- Programming microcomputers

Through this wide variety of topics and experiments, students learn how to use instruments and tools, and they develop a physical sense for measurement.

\section{Pressure to Change}

Industry used to support the standard educational approach that emphasized fundamentals. The belief, borne out through practice, was that students well-grounded in fundamentals could be effectively developed into professional engineers or specialists by "on-the-job" training in industry. This method of education is under pressure to change. Industry now needs engineers who must compete in an environment characterized by reduced development times, lower development budgets, and increased expectations of quality. All of these demands are presented within a new framework of intense global competition.

Additional pressure is also due to shortages of qualified engineers. Nowhere is this more evident than in industries that depend on digital technologies. Modern industrial products are almost always equipped with a microprocessor and memory. This computing power is used to perform control, auto- matic calibration, noise cancellation, and other digital signal processing operations.

\section{Impacts of the Digital Revolution}

The impact of innovations directly attributable to digital technology has been substantial. Measurement sophistication can be built into the most basic of instruments. Adding it is cost-effective because component costs are low, and good development tools are widely available. For Japanese industry, the major impact of the digital revolution has been the steady erosion of Japan's enviable position with respect to quality, which was sustained largely by faithful adherence to standards. We are now faced with intense global competition from international companies that have employed digital technology to substantially increase product quality. To win the global competition, industry demands young engineers who have many detailed professional skills, and it wants engineers who understand a systems approach to problem solving.

This impact has been felt in the I\&M curriculum. Universities have responded to this challenge by adding new elective courses at the undergraduate and graduate levels. New professional graduate education programs also have been added. Typical measurement courses offered at the graduate level include:

- Microwave measurements

Optical measurements

- Digital instrumentation

- Biomedical measurements

Typical topics covered in Microwave and Optical Measurement courses are listed in Tables 3 and 4 [1]-[3].

Making changes is not easy. Creating a course and deciding on content is left to the discretion of the instructor. This approach has pitfalls. Sometimes the same topics are covered by several courses, or some important topics such as data acquisition, digi- 
Table 2. Syllabus of Two-Credit "Electronic Measurements" Course.

\section{Introduction}

Objectives and Merits of Electronic Measurements

Measurement Systems

Analog and Digital Measurements

Data Processing

Extracting Information

Digital Data Processing

Error Analysis

Data Conversion

Transducers

Analog Quantities

Analog-to-Digital Conversion

Electronic Instruments

Signal Sources

Counters

Digital Multimeters

Power Meters

Impedance-Measuring Instruments

Waveform Analyzers

Oscilloscopes and Displays

Recorders and Data Loggers

Digital Instrumentation

Digital Instrumentation Systems

Interfaces

Controllers and Data-Acquisition Systems

High Frequency Measurements

Measurements of Transmission-Line Parameters

Noise Measurements

Optical Measurements

Spectroscopy

Interferometry

Holography

Table 3. Syllabus of "Microwave Measurements" Course.

Electromagnetic Waves and Transmission Lines

Maxwell's Equations

Networks and Transmission Lines

Microwave Networks

Networks and Circuits

Network Parameters

Parameter Measurements and Errors

Impedance Measurements

Impedance and Reflection Coefficient

Voltage Standing Wave Ratio

Classified Measurement Methods

Reflection Standards

Reflectometers

Three-Port Networks

Attenuation and Phase Measurements

Standard Components

Measurement Methods

Measurements of Network Parameters

Network Analyzers

Six-Port Measurements

Thru-Reflect-Line Calibration

tal signal processing, and system identification, are missing. To improve this situation, we have initiated a review of the undergraduate and graduate curricula. Can this review bring about a significant improvement? There are no simple answers.

\section{Challenges to Improving I\&M Education}

One impediment to change is the system used for evaluation of faculty. Contributions to education are not taken into account. The evaluation is based entirely on the number of papers published, the number of citations, and the total research funding earned. Trying to infer professional quality from quantity seems to be an international problem, and has contributed to the proliferation of trivial papers submitted to
Table 4. Syllabus of "Optical Measurements" Course.

Fundamentals of Optical Technology

Light Sources

Optical Detectors

Optical Elements

Optical Fibres

Noise

Length Measurements and Ranging

Laser Radars

Interferometry

Triangulation

Moire Fringes

Velocity Measurements

Doppler Methods

Correlation Methods and Speckle

Spatial Gratings and Filtering

Fiber-Optical Gyros

Shape Measurements

Imaging

Holography

Moire Topography

Laser Scanner

Surface Inspection

Random Surface Profilometry

Light-Scattering Techniques

Automatic Focusing Techniques

Spectroscopy

Fabry-Perot Interferometers

Mach-Zehnder Interferometers

Fourier Spectroscopy

Multispectrum Scanners

Performance of Optical Measurement Systems

Sensitivity

Resolution

Noise

IEEE Transactions and other journals. If the resumes of two groups of professors are compared-one group engaged in research and the other engaged in technology development-the research-oriented faculty is found to have many more papers than the technology-development-oriented faculty. This result also holds true for research funds. Grants from the Japanese Ministry of Education (similar to the National Science Foundation in the U.S.) are mostly directed to scientific research and not technology development. This is not to say that scientific research makes for an easier time, but the motivation drives most faculty to seek research opportunities. The result is that most professors in EE departments are engaged in work that is more likely to be in the realm of material sciences than it is to be in technology-oriented topics such as communications, control, circuits and systems, signal processing, and I\&M.

The digital-technology revolution shows up again. This time, it is working against education. Students become accustomed to easy-to-handle digital instruments. They feel satisfied when they can easily take millions of data points, yet have no motivation to develop insight into the physical nature of the phenomena they are measuring. Nor is the tendency to prefer a "clean" digital technology to a "muddy" old technology confined only to instrumentation. It is common in other fields as well. Students are interested in the latest fashions, dreaming their fashionable poses in front of a computer desk. "Neural" and "fuzzy" sound very attractive; the Bode diagram and Nichols chart are nothing but trivial past inheritances. 


\section{The Future of Instrumentation and Measurement Education in Japan:}

\section{An Industrial Perspective}

Mitsuhiko Nagata

W e have entered an era in which change is the only constant. The continued dramatic changes in the world's political situation have broken down many territorial barriers and unleashed global economic competition on a scale never imagined. To thrive in this new climate, it is essential that companies design products that achieve global acceptance while meeting global standards. There are entirely new issues, such as environmental protection and sustainability, that are now very important. In addition to the traditional economics of developing and selling products, we must now save natural resources through minimizing material consumption and increasing the ability to recycle. Companies must achieve strategic advantages through developing products that meet the needs of modern industry. Key features in demand to meet complex, precision control requirements are small size and high accuracy. And, this is happening. Products have become more and more complex, specialized, and smaller. Resolution and accuracy are steadily improving. If $10 \mathrm{~ms}$ was sufficient resolution for yesterday's equipment and processes, better than 1 $\mathrm{ms}$ is now required. Micro-scale technology is now nano-scale technology.

\section{THE PRESSURES OF INNOVATION}

Over the last two decades, continued innovation in digital technology has completely changed the field of instrumentation and measurement. Increasing performance and falling chip prices have made powerful and easy-to-use digital technologies widely available. Almost any advanced I\&M product has embedded digital signal processing (DSP) that includes a central processing unit with almost unlimited memory. Incorporating DSP results in high performance and delivers powerful features such as automatic calibration, statistical calculations, data storage, data conversion, and so on. And, if that were not enough, it can also be done at lower cost.

The extraordinary movement toward digital technology is not without cost. We are losing a fundamental understanding of natural phenomena and behavior. Paradoxically, instrumentation shares the blame. The basis for this understanding is in the natural sciences. And, to understand nature, I\&M technologies are among the first important steps. We now have engineers relying too much on advanced instrumentation. Plug-and-play concepts from the digital world have been adopted, with disastrous results for engineers using complex measurement instruments. An engineer can easily acquire millions of data points, store them in their unlimited storage media, put the data in a spreadsheet, and perform statistical calculations. They can use this complex equipment, yet don't understand the details of what they are measuring. Once the data has been converted from analog to digital form, the accuracy of data and number of significant digits no longer interests them. It is too easy to just let a computer calculate "some" value. Many digits of data convey a false sense of accuracy and information. Measurement condition, accuracy, and resolution always have to be carefully examined to obtain valuable data. Many times, valuable information is buried in large volumes of data that need to be properly analyzed and processed. The only cure is a systematic
The real danger is that it is too easy to play around using software like MATLAB that acts more like a toy than a serious tool. What this means is that students are enjoying an easy-going life in the dimensionless, virtual world of a computer simulation, but are not learning enough about the real, dimensioned world where they must practice engineering. There are simply too few students who are interested in learning a rigorous problem-solving method that requires a systematic approach based on the step-by-step accumulation of knowledge.

These facts suggest a dismal prospect for improving I\&M education.

\section{No Measurement, No Industry}

I\&M technology has served as the backbone of modern industry. But even more important, the creation of new industries and reshaping of old industries are also dependent on measurements. Only those physical or chemical phenomena confirmed by measurements can be the seeds for new industries. Thus, industries are eager to get highly educated instrument engineers. We cannot lose hope when confronted by what appears to be the dismal future of I\&M education. There are several steps that we need to take immediately in order to meet these challenges. 
approach to I\&M education that includes improving the basic understanding of the natural sciences. Now is the time to review what we are doing and renew our commitment to change.

To be globally competitive, engineers must now effectively handle a wide variety of technologies. For example, integrating electronics and mechanics is no longer a curiosity. Mechatronics-the union of electronics with mechanics-is a common requirement. Similarly, hardware and software need to be effectively integrated in order to get maximum performance. The result is that a wide range of detailed, expert skills are required to realize these new generations of products that actually deliver small size and high accuracy. What's needed is an engineer with both expert knowledge and training in a systematic approach.

The most essential skill for engineers on the job is problem solving. Engineers spend their days analyzing the current status of processes, identifying issues to be resolved, determining the plans of action needed to solve them, and then finally finding solutions. However, due to the complexity of modern technologies, identifying real issues has become more difficult. Advanced skills are required to plan and carry out the good measurements crucial for identifying the key issues. On-the-job training for engineers is an ongoing challenge.

Due to system complexities and the details of the analog and digital elements needed to implement them the basic education of engineers is very important. Added to those complexities and details are the system, hardware, and software tradeoffs that must be made.

\section{CURRICULUM RECOMMENDATIONS}

Significant improvements in I\&M education would be gained if the following topics were covered:
Basics of natural science

- Basics of I\&M science

- Basics of analog data handling

- Basics of digital data handling

- Statistics

Studying the in-depth details of certain areas can help educate students in a general

problem-solving approach. This is very important for engineers who will practice in industry. Rapid growth of new technologies, especially in the digital world, makes industry look to recent graduates for significant help. These young engineers must be well versed in problem solving using modern technologies. This combination of skills makes them able to contribute immediately to product development. The desire of students to specialize in an interest area needs to be balanced against the important need to develop their problem-solving abilities and fundamental understanding of natural science.

We have entered a new age of industrial revolution. Rapid growth in key technologies-digital technologies in particular-has created pressure to reform I\&M education. New partnerships will be required between industry and academia to develop the new educational models needed to meet the challenges of the 21 st century.

Mitsuhiko Nagata received his bachelor's degree from the Science University of Tokyo in 1981, and joined Yamatake-Honeywell Co., Ltd. (currently Yamatake Corporation) in 1981 as a Research and Development Engineer. Nagata worked on thin-film sensors at the Corporate Research Center until 1995, and is currently an Engineering Manager in the Control Products Division.

\section{Upgrading Content}

Some ideas for new topics were suggested earlier. However, there are many others. For example, automated and networked instrumentation, fault tolerance, diagnosis for quality control, and high-yield production, should all be included in a curriculum. But it is not enough to add a few advanced courses; we must also strengthen the supporting courses so topics such as analog and digital signal processing, system identification, and neural and fuzzy technologies can be presented. Biomedical, environmental, optical, materials characterization, and sensor technologies are major new branches of instrumentation that our students need to learn. These are likely to be the seeds of the industries of the 21st century.

How can these topics be effectively delivered? Covering such a wide variety of topics is virtually impossible for a small minority at one university. Yet, through cooperation and exchange among many universities, it ought to be possible to deliver a complete spectrum of topics.

\section{Delivering the Physical World}

Engineering is the accumulation of know-how. The only opportunity for students to get the know-how and a physical sense is through lab experiments. Teaching relevant theories 
in lecture courses concurrently with lab experiments, and confirming the theories and experimental results by computer simulations will be the most desirable and efficient approach to engineering education [4], [5]. "Do it yourself" is the spirit of lab experiments. Students may fail in building experimental apparatus, but they can learn much from their failures.

Lab experiments burden teaching staffs. The types of apparatus and facilities are limited. These issues can be solved, however, by offering prototypes developed by professors' research activities or by finding good materials in Transactions papers. Practice in industry during vacations will be an alternative.

\section{Organizational Challenges}

The IEEE I\&M Society has recently formed a technical committee (TC) that is charged with the task of addressing instrumentation education. The Education for I\&M TC will host an open-discussion forum at the next I\&M Technology Conference, IMTC/99, which will be held May 25-27, 1999, in Venice, Italy. This is an important first step. Unfortunately, in Japan, such reform movements have not happened to date. I\&M topics are distributed over four institutes. The Institute of Electrical Engineers (IEE), Japan, has traditionally covered electrical and electronic measurements. The Society of Instrument and Control Engineers, Japan, derived from the IEE, mainly covers industrial process control and measurements. Optical measurements and sensors are covered by the Japan Society of Applied Physics. Another society, The Institute of Electronics, Information, and Communications Engineers, Japan, also publishes textbooks on electronic measurements for the fundamental courses [6], [7]. In addition, the Tokyo Chapter of the IEEE I\&M Society is another strong partner.

There are some obvious steps that need to be taken. First, IEE needs to join the IEEE I\&M Society's education TC. Then, IEE should call for participation from the other societies in the education program. This should not be difficult to do; a good prototype is the Electronic Circuits Committee of the same institute, which, in cooperation with the Tokyo section of the IEEE Circuits and Systems Society, has invigorated circuits education and research through frequent open forums and workshops.

\section{Compiling the Best}

It is critical that information about new technologies and new solutions be conveyed to new generations of instrumentation engineers. However, engineering education can pass on only those technologies that are organized systematically. Every year many good papers are published in the journals of the many Japanese, European, and U.S. societies. This material is often useful for graduate courses, but the fragmentary nature of many independent sources makes it difficult to transmit a coherent body of knowledge. Furthermore, it is easy to lose knowledge when it is so widely dispersed. Even the best technical paper is never as effective as a good textbook; instrumentation education is seriously hindered by the lack of good textbooks. In fact, volume 12 of Electronic Measurements and In- strumentation, of the Inter-University Electronics Series published by McGraw-Hill in 1971 [8] is the only English instrumentation textbook on my bookshelf.

For an example of how effectively organized information can change technology industries, consider the MIT Radiation Laboratory Series [9]. This 28-volume series once greatly contributed to the development of microwave engineering and industry. It is time to put together a similar series to serve our needs. The same spirit of cooperation among the U.S., Canada, and England that went into the original MIT series can serve as the model for an international series that captures the full breadth and depth of I\&M technology. The IEEE I\&M Society should organize and lead this effort. The international I\&M community cannot afford to postpone this critical effort.

\section{Acknowledgments}

The author thanks M. Nagata, Yamatake Corp., for his comments, which provided an industrial perspective.

\section{References}

[1] T. Iwasaki, Fundamentals of Microwave and Optical Circuit Measurements, Tokyo: Society of Instrument and Control Engineers, 1993 (Japanese).

[2] P. Cielo, Optical Techniques for Industrial Inspection, San Diego: Academic Press, 1988.

[3] T. Fujimura, Ed., Fundamentals of Optical Measurements, Tokyo: Morikita Shuppan, 1993 (Japanese).

[4] J.M. McMenamin, Linear Integrated Circuits, Englewood Cliffs, NJ: Prentice-Hall, 1985.

[5] S.A. Dyer and R.A. Dyer, "Emphasizing the interdependence of topics in required undergraduate electrical engineering courses: a case study," in Proc. IEEE Instrumentation and Measurement Technical Conference, Ottawa, Canada, pp. 1320-1325, 1997.

[6] M. Kanno, Electrical and Magnetic Measurements and Instrumentation, Tokyo: Corona Publishing, 1992 (Japanese).

[7] Y. Tsuzuki, Electronic Instrumentation, Tokyo: Corona Publishing, 1991 (Japanese).

[8] B.M. Oliver and J.M. Cage, Eds., Electronic Measurements and Instrumentation, New York: McGraw-Hill, 1971.

[9] C.G. Montgomery, Technique of Microwave Measurements, Boston: Boston Technical Publishers, 1964.

Kenzo Watanabe received his B. Eng. and M. Eng. degrees from Shizuoka University, Hamamatsu, Japan, in 1962 and 1966, respectively, and his Dr. Eng. degree from Kyoto University in 1976. He is presently a Professor with the Research Institute of Electronics at Shizuoka University. He received the Andrew R. Chi (Best Paper) and Society Awards from IEEE IEM Society in 1984 and 1998, respectively, and Saito and Takayanagi Awards in Japan in 1990 and 1994, respectively. He is a Fellow of IEEE and serves as an Associate Editor of the IEEE Transactions on Instrumentation and Measurement. He contributes to the creation of new industries in Shizuoka Prefecture through his leadership role in cooperative research projects among academia, industry, and government. 